\title{
INNOVATIONS IN ASTRONOMY AT THE OPEN UNIVERSITY
}

\author{
Barrie W. Jones \\ Physics Department, The Open University, Milton Keynes MK7 6AA, U.K.
}

\section{Introduction}

Dreary correspondence colleges that send tatty typewritten notes to their suffering students are gradually being eclipsed by full-fledged open-learning institutions of wide educational significance. The Open University is the premier open-learning institution in the U.K., perhaps even in the world. It already offers an astronomy course as a significant part of a science major degree, and further courses are planned, including an in-service course for school teachers.

In this article I discuss:

1. open learning systems, including the ways in which various educational media can be used to good effect

2. some features of the existing astronomy course of The Open University, and some possibilities for future courses.

\section{Open Learning Systems}

There are still comparatively few open-learning institutions in the world, though their numbers are growing. They all differ strikingly from conventional educational institutions but nevertheless the materials they produce have been used successfully by conventional institutions, and many of their educational strategies and techniques have been put to good effect very widely in education, including within the third world. Let's look at some of this in more detail via the specific case of The Open University.

\subsection{The Open University}

The Open University (OU) was founded in 1969 for the specific educational purpose of providing adults with the opportunity to study at tertiary level in their own homes in their own time. It offers fully recognized bachelor's degrees, higher degrees, and a great variety of short courses. It accounts for nearly all of the open learning at tertiary level in the U.K., and currently it has 68,000 undergraduates. Over half of those who start on degrees obtain them.

The OU is open in four distinct ways.

(i) To qualify for entry, students need only be 21 or over and be resident in the U.K. 
(ii) Students can study almost exclusively in their own homes or workplaces.

(iii) Students can study in their own time and, within loose constraints, can progress towards a degree at their own rates.

(iv) Student fees cover only a small fraction of the tuition costs: an honors degree costs a student on average, about $\$ 4,000$ at current prices. (The difference is provided by the U.K. government.)

The OU uses a rich array of media to educate its students, and a great deal of thought and production resource goes into each medium. Table 1 lists most of the media that we use, and any particular course will use most of these.

Table 1. Media Used

\begin{tabular}{|c|c|c|c|}
\hline Printed materials & $\begin{array}{l}\text { - the main texts } \\
\text { - supplementary } \\
\text { materials }\end{array}$ & $\begin{array}{l}\text { Face-to-face } \\
\text { teaching }\end{array}$ & $\begin{array}{l}\text { - small group tutorials } \\
\text { - residential schools }\end{array}$ \\
\hline Audiovision & $\begin{array}{l}\text { - broadcast } \\
\text { television } \\
\text { - videocassettes } \\
\text { - audiocassettes }\end{array}$ & $\begin{array}{l}\text { Assessment } \\
\text { of students }\end{array}$ & $\begin{array}{l}\text { - continuous assessment } \\
\text { - computer marked } \\
\text { - tutor marked } \\
\text { - final examination }\end{array}$ \\
\hline \multicolumn{2}{|c|}{$\begin{array}{l}\text { Computer-assisted learning } \\
\text { (including videodisc) }\end{array}$} & \multicolumn{2}{|c|}{$\begin{array}{l}\text { Feedback from students and tutors } \\
\text { to the course team. }\end{array}$} \\
\hline \multicolumn{4}{|c|}{ Home experiment kits } \\
\hline
\end{tabular}

A course is produced by a team of people. The team defines the content and the general approach, and for each medium the team discusses the material at each of various stages in its production. For example, in the case of the main texts, an author, who is normally a member of the team, has to write to a fairly tight brief, and has to suffer course-team discussion of several drafts. This is ideal for those who like delivering public whippings (and also for the smaller number who like receiving them), but nevertheless we believe that the course-team mode of production improves the quality of all of the various media that we use.

The courses are designed and produced at the main campus in Milton Keynes (where the research laboratories are also housed). In addition there are 13 regional offices, the main job of which is to sustain the regional support system, notably the appointment of part-time tutors and the organization of the non-academic aspects of tutorials and residential schools.

\subsection{The Use of Various Media}

From the long list in Table 1, I'll examine the use of just a few.

First consider, the main texts. At the OU these are the main teaching vehicle, and this will remain the case until almost everyone in the U.K. has easy local access 
to videocassette players, microcomputers, or whatever else is required for a medium that replaces the printed page. This means that for the distance learner, even in the U.K., the printed page will be predominant for the foreseeable future, the other media finding a more prominant place at residential schools or in tutorials.

We write our own main texts and make relatively little use of available textbooks. This is because for the distance learner it is particularly important that a text is more "user friendly" and student-active than the usual textbook. Note that any student can benefit from a text designed initially for the distance learner.

Second, consider broadcast television and videocassettes. Broadcast television programs are made on the assumption that students do not record them, whereas videocassette programs are either loaned to students on already recorded videocassettes or the assumption is made that the students will record them off the air when the programs are broadcast (which can then be in the middle of the night). Thus, broadcast television should be used in a different way from videocassette because of the ephemeral nature of television compared to the replay and freeze facilities available with videocassette.

In particular, broadcast television programs should have a soft pedagogical role: low density teaching; showing students places and situation beyond normal reach; and telling the story of a discovery, an experiment, or a theory. By contrast, videocassette programs can have a hard pedagogical role: high-density teaching; interactive/student active teaching; and visuals with intricate details.

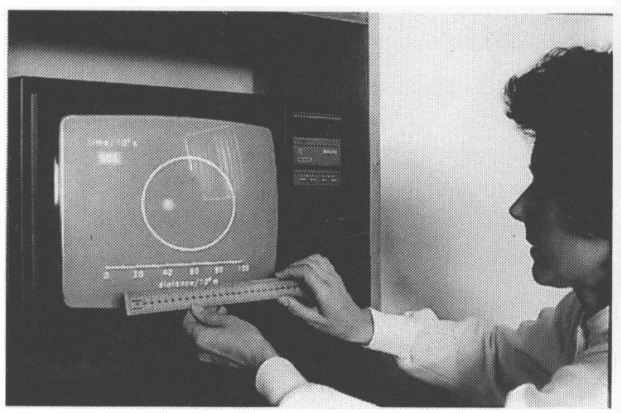

Fig. 1. A student working with the videocassette supplied as part of The Open University course Matter in the Universe.

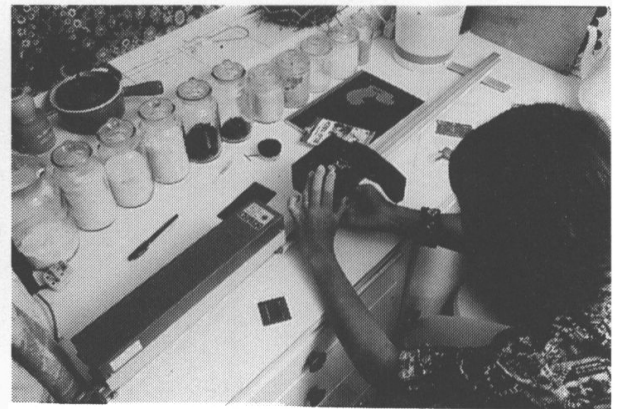

Fig. 2. A student (in 1978) making a hologram at home with the home-experiment kit supplied with The Open University course Images and Information.

Fig. 1 shows a student working with the 120-minute videocassette supplied as part of the OU astronomy course (see Sect. 3.1). In this particular example the student is observing the motion of a small body around a far more massive body: by taking off-screen measurements of the orbital semi-major axis and orbital period, the mass of the larger body will be obtained. More complicated cases then follow. This videocassette contains much else, including a simulation of the spiral density-wave 
in spiral galaxies.

Finally, consider home-experiment kits. These provide the student with the opportunity to do experimental and observational science at home, though the lack of supervision can be a problem. Nevertheless it is surprising what can be achieved: in Fig. 2, a (1978) student of our optics course is shown making a hologram at home - yes that is a laser. However, a good deal about experimental and observational science, including astronomy, can be learned with far simpler equipment, indeed with little if any more than the sort of things that can be found around the average household, even in the less wealthy parts of the world.

\section{Astronomy Courses at The Open University}

\subsection{Matter in the Universe}

Matter in the Universe is the OU astronomy course, and it comprises $1 / 16$ of a general bachelor's degree with honors. Table 2 lists the major topics covered, with the approximate fraction of the course devoted to each of these. The course has a few unusual features, as follow.

Table 2. Matter in the Universe

\begin{tabular}{lc} 
Subject area (in order) & \% of course \\
\hline Introduction and overview & 6 \\
The interstellar medium & 25 \\
Stars & 32 \\
Galaxies & 12 \\
Planetary systems & 25 \\
\hline
\end{tabular}

First, it is apparent from Table 2 that the interstellar medium is prominent in both position and fraction of the course. This induces culture shock in many of our students, who come to the course thinking that astronomy is only about stars, planets, and galaxies. However, we believe that the interstellar medium deserves its prominent role.

Second, we use a story line to link together much of the course. We took as our story line the evolution of matter in the cosmos, not only within galaxies from the interstellar medium to the stars and planets, with the subsequent return of some of this material, somewhat modified, to the interstellar medium - but also the evolution of the galaxies themselves.

Third, students are not shielded from the uncertainty that still pervades much of astronomy, and linked to this we have a yearbook to update the course.

Fourth, the course shows that astronomy both draws on and feeds into other subject areas - a two-way process.

Finally, and related to the previous point, we teach the underlying physical and chemistry not taught elsewhere in prerequisite OU courses. The physical examples will probably be familiar to you (spectroscopy, nuclear physics, etc.), but the 
chemical examples, relating mainly to the interstellar medium (ISM), will probably be less familiar:

- the ISM is far from thermodynamic equilibrium, so we teach some non-equilibrium chemistry and chemical kinetics

- the ISM contains appreciable concentrations of ions and these react readily, so we teach something of ion-molecule reactions

- the best way to make $\mathrm{H}_{2}$ in the ISM is probably on dust-grain surfaces, so we teach something about reactions on solid surfaces (once we have $\mathrm{H}_{2}$, gas-phase reactions seem able to provide the other molecules).

The course is now in its fourth year of presentation. It is a rather high level course, but nevertheless attracts over 400 students per year, over 60 per cent of whom successfully complete the course.

\subsection{Possible Future Courses}

The possibilities for future OU courses in astronomy are legion, but life is short and resources are limited. There is however a pressing opportunity arising from the recent specification in the U.K. of a national science curriculum for schools, to be implemented starting in autumn 1989. This curriculum includes some astronomy, and so there is now an urgent need to provide teachers with the necessary astronomical background via short in-service courses. Development is under way.

Less pressing, but highly desirable, is an undergraduate astronomy course at a lower level than Matter in the Universe, and somewhat broader. This would be a general-appeal "astronomy for poets" course similar to the many liberal arts courses taught in the U.S.A. and Canada.

Astronomy is certainly alive at The Open University, but there are many opportunities for us to do a lot more, both within the U.K. and beyond.

\section{Discussion}

S. Torres-Peimbert: For how long has the astronomy course been given? How many students have taken it? What are the results?

B. Jones: The astronomy course has been running each year since 1985 . Over 400 students start it each year, and over $60 \%$ of these achieve a full pass.

R. Ramkarthikeyan: What do you do for practicals in the "open university"?

B. Jones: We send out home experiment kits (one contains an optical bench, laser, etc.) for unsupervised use at home. We also have day schools around the U.K., and summer schools, for supervised laboratory and field work. Overall we have somewhat less practical work than at a conventional university.

A. Cool: How is The Open University funded, and how much does it cost a typical student to complete the degree? 
B. Jones: The Open University is largely funded by central government, with much smaller contributions from other bodies, including foundations and industry. The students on degree courses pay only a small fraction of the true costs.

Roughly speaking, it costs about $\$ 4,000$ to obtain a full honors degree, and this will be spread over, typically, six years.

\title{
A SELF-PACED MASTERY-ORIENTED INTRODUCTORY ASTRONOMY COURSE
}

\author{
John L. Safko
}

Department of Physics and Astronomy, University of South Carolina, Columbia, South Carolina 29208, U.S.A.

I will be describing a self-paced mastery-oriented introductory astronomy course that has been offered at the University of South Carolina since 1972. This course is a three-semester sequence with total enrollments of 800-1000 students per term. Most of the enrollment is for the first semester of the sequence. Although these particular courses are designed for non-science majors, I believe that the methods developed in these courses can be applied to courses for astronomy majors. These methods could provide a solution to the problems of teaching classes and, at the same time, traveling for research and meetings.

A mastery-oriented course involves developing a list of learning objectives that are described in terms of performance of given tasks. That is, words such as understand and appreciate should not be used. Performance objectives involve words such as recognize, calculate, measure, and describe. Any set of learning objectives must be tied to a set or readings, a textbook, and/or supplementary notes. These items are chosen or written by the instructor(s) to provide the background necessary for the students to master the objectives.

At the University of South Carolina, our learning objectives were developed by examining the test questions that had been collected from 5 years of a regular lecture course. This allowed us to determine what performance we were expecting from the students, rather than guessing what the learning objectives should be. In a few cases it became obvious that additional objectives and/or additional questions were needed. In some cases it was clear that questions should be eliminated. Item analysis and student questions told us what notes in addition to the text were needed. We combined the objectives, the notes, and the laboratory materials that we use into a single volume.

A regular text publisher would want modifications in order to sell sufficient copies to justify publication. Rather than remove all references to particular procedures at our institution, we chose to go to a publisher who prints and ware- 